\section{Migraine and vertigo}

Neuhauser et al. (p. 436) studied 600 subjects: 200 with migraine, 200 with dizziness, and 200 orthopedic control patients. They assessed dizzy patients for migraine and all subjects for migrainous vertigo. Migraine was frequent in patients with vertigo (38 versus $24 \%$ in controls) and migrainous vertigo was frequent in both migraine and dizzy patients. The accompanying editorial by Stahl and Daroff (p. 428) emphasizes the importance of this study-recognizing that dizziness can be caused by migraine-both for treatment strategies and for understanding the pathology of miraine.

\section{Repetitive transcranial magnetic stimulation (rTMS) improves cognition}

Boroojerdi et al. (p. 526) studied the effect of rTMS on tests of memory and reasoning. They detected an effect of stimulation of the left prefrontal cortex on analogic reasoning: rTMS accelerated solution time. The accompanying editorial by Triggs and Kirshner (p. 429) traces the development of rTMS and considers the possibility that it may not only aid in the localization of CNS function, but may have therapeutic uses.

\section{Chronic inflammatory demyelinating polyradiculoneuropathy (CIDP): Controlled trial of IV immunoglobulin (IVIg)}

Mendell et al. (p. 445) studied IVIg as the initial treatment in 53 CIDP patients (30 IVIg versus 23 placebo). IVIg improved muscle strength significantly by day 10 with benefit continuing for 6 weeks.

\section{Gaze-evoked tinnitus (GET): Localization by PET \\ Lockwood et al. (p. 472) followed up on their earlier work in tinnitus (Neurology 1998;50:114-120) by studying the tinnitus that is associated with lateral gaze in}

patients with eighth nerve pathology usually following cerebellopontine angle surgery. With lateral gaze, tinnitus increased in loudness and pitch. PET showed that GET was associated with neural activity in the auditory areas of the lateral pontine tegmentum and cortex.

\section{Anoxic-ischemic encephalopathy (AIE): Early MRI changes in white matter} Chalela et al. (p. 481) obtained conventional and diffusion-weighted MRIs on seven AIE patients a mean of 2.5 days postinsult. Restricted diffusion was symmetrically distributed in the white matter: periventricular, corpus callosum, and internal capsule. Gray matter showed less involvement by diffusion-weighted imaging (but more on conventional MRI).

Although gray matter has been considered more vulnerable in AIE, the study by Chalela et al. supports animal data indicating that white matter is very susceptible to injury.

\section{Genetic risk factor for stroke in Chinese patients}

The incidence of ischemic stroke is higher than coronary artery disease (CAD) in Chinese patients. Hou et al. (p. 490) studied a genetic marker of endothelial constitutive nitric oxide synthase (ecNOS) and found that an ecNOS allele was associated with a 2.4-fold greater risk of ischemic stroke. (In another, earlier study this allele was associated with CAD in Australia.)

\section{Quantifying cough in stroke predicts aspiration risk Smith Hammond et al. (p. 502) evaluated quantitative cough measures (inspiration phase flow, expulsive phase flow, rise time, volume acceleration, and sound pressure level of cough) in aspirating and nonaspirating stroke patients as well as in normal controls. All were impaired in aspiration, with rise time independently associated with aspiration severity.}

Mortality in epilepsy patients Racoosin et al. (p. 514) examined five New Drug Applications for epilepsy treatments submitted to the US Food and Drug Administration in the last decade to determine the incidence of and risk factors for sudden unexpected death in epilepsy (SUDEP). Data were available on 1,293 monotherapy patients and 9,144 "add-on" patients. SUDEP did not occur in monotherapy trials (nearly 1,000 person-years) but occurred in 52 patients in add-on therapy trials (over 13,000 personyears). Their data suggest that disease severity is the major risk factor for SUDEP. $\bullet$ Walczak et al. (p. 519) prospectively studied mortality in 4,578 patients followed for 16,463 patient-years. SUDEP accounted for $18 \%$ of all deaths. Risk factors for SUDEP included tonicclonic seizures, treatment with two or more antiepileptic drugs, and $\mathrm{IQ}<70$.

\section{Cessation of TIAs with statin use}

In a prospective study, statin therapy for coronary artery disease was associated with a decreased risk of stroke and TIA. M.J. Alberts (p. 531) reports two patients in whom recurrent TIAs stopped abruptly with the initiation of a statin, suggesting a direct effect on the mechanism of the TIAs.

\section{Clinical deterioration following initial improvement with tissue plasminogen activator (tPA)}

The clinical improvement seen with tPA therapy can be followed by deterioration (15\% in one series). Burgin and Alexandrov (p. 568) followed such a patient and found evidence for reocclusion by transcranial Doppler (TCD). Angiography confirmed the occlusion and intra-arterial tPA reversed it. TCD deserves study in other such patients who deteriorate. 


\section{Neurology}

\section{February 27 Highlights}

Neurology 2001;56;427

DOI 10.1212/WNL.56.4.427

This information is current as of February 27, 2001

\section{Updated Information \&} Services

Permissions \& Licensing

Reprints including high resolution figures, can be found at: http://n.neurology.org/content/56/4/427.full

Information about reproducing this article in parts (figures,tables) or in its entirety can be found online at:

http://www.neurology.org/about/about_the_journal\#permissions

Information about ordering reprints can be found online:

http://n.neurology.org/subscribers/advertise

Neurology ${ }^{\circledR}$ is the official journal of the American Academy of Neurology. Published continuously since 1951, it is now a weekly with 48 issues per year. Copyright . All rights reserved. Print ISSN: 0028-3878. Online ISSN: 1526-632X.

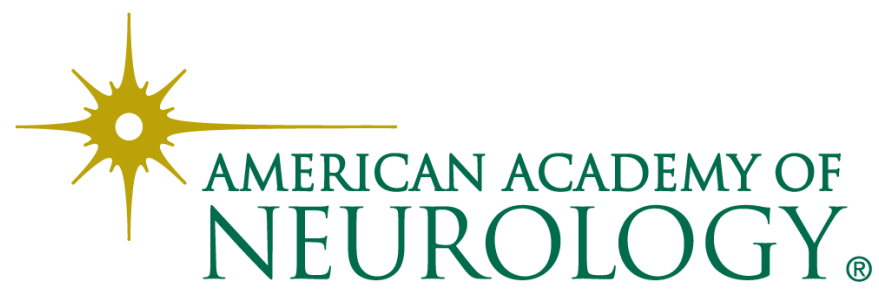

